Military Technical College

Kobry El-Kobbah, Cairo, Egypt

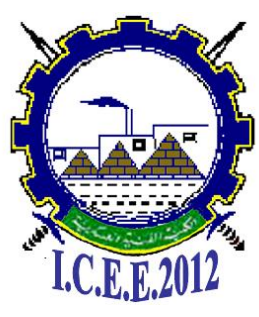

$6^{\text {th }}$ International Conference

on

Chemical \& Environmental

Engineering

29 - 31 May, 2012

CEEA-1

\title{
KINETICS AND PROCESS DESIGN FOR ADSORPTION OF MAXILON RED DYE FROM AQUEOUS SOLUTIONS USING GAS MIXING
}

\author{
Mamdouh Mahmoud Nassar*, Taha Ebrahiem Farrag*
}

\begin{abstract}
The gas mixing technique was used to study the kinetics of adsorption of a dye from its solution. Equilibrium and kinetic studies were investigated for the adsorption of Maxilon Red BL-3 onto a low cost adsorbent (natural clay). Linear regression was used to determine the best fit of equilibrium and kinetics expressions. The two parameters models including Freundlich, Temkin, Dubinin-Radushkevich and four different linearized forms of Langmuir were employed for fitting the equilibrium data. Type I of Langmuir model was found to be the best model that represents experimental data and the monolayer adsorption capacity was determined as $344.83 \mathrm{mg} / \mathrm{g}$ at $25^{\circ} \mathrm{C}$. Factors influencing dye adsorption such as gas flow rate, initial dye concentration and temperature were investigated. Four kinetic models, pseudo firstorder, pseudo second-order, Elovich and fractional power kinetic models were selected to follow the adsorption process. A comparison of the kinetic models on the overall adsorption rate showed that the adsorption system using gas mixing was best described by pseudo second-order kinetics. Based on the sorption isotherm relations obtained a single stage batch adsorber was designed for different initial dye concentrations to calculate the optimum effluent volume based on dye concentration/adsorbent mass ratio.
\end{abstract}

Keywords: Gas mixing, Equilibrium, Kinetic models, Natural clay, Batch adsorber.

\footnotetext{
* Chemical Engineering Department, Faculty of Engineering, El-Minia University, El-Minia, Egypt, Corresponding author:

Fax +2086-2346674; email: tahafarrag@ @otmail.com
} 


\section{Introduction}

Dyes are the major pollutants of waste water from textile, cosmetic, paper and coloring industries. The discharge of colored effluents into rivers upsets biological activity so that removal of dyes from waste effluents becomes environmentally important. Conventional treatment methods for removal of pollutants from aqueous solutions, like photochemical degradation, biological degradation, coagulation, chemical oxidation and adsorption have been investigated with varying success [1,2]. Between the mentioned methods, adsorption is one of the potential methods for the removal of dye compounds from water. Different adsorbents can be used for pollutants removal, and, certainly, the cost is an important parameter for the application of any of them. That is why alternative adsorbents have been investigated for the treatment of dyes. Many of these adsorbents are natural materials available in large quantities, or low pried waste products.

Clay has been accepted as one of the most appropriate low cost adsorbents for removal of dyes from wastewater. Among the clays studied, bentonite has received considerable recognition as an adsorbent. It is hydrated alumino-silicate clay primarily composed of the smectite-class mineral montmorillonite [3-5]. It is well known that the negative charge of clays is balanced by exchangeable cations, which are usually $\mathrm{Na}^{+}$and $\mathrm{Ca}^{2+}$ [5]. The wide usefulness of clay minerals is essentially a result of their high specific surface area, high chemical and mechanical stabilities, and variety of surface and structural properties [6].

Multiphase flows are found in many applications of interest to industry. Bubble column reactors represent one broad class process equipment important to several industries in which multiphase flow phenomena dominate. Examples include oxidation reactors used in the petrochemical industry, devices used in microbial fermentation and treatment of wastewater in biochemical/environmental industries. The widespread industrial applications of bubble column is due to their simple construction, large effective interfacial area and high mass transfer rates [7,8]. Little attention was given to using gas sparged column as an adsorber.

Previous studies on energy consumption and mass transfer during adsorption of dyes on clay using mechanical and gas stirring proved that not only gas stirring enhances the efficiency of dye adsorption but also the energy consumption was substantially lower for air stirring; approximately 60 times lower than for mechanical stirring under identical conditions of adsorption [9]. The high efficiency of gas stirring in increasing the rate of mass transfer compared to single phase flow was attributed to the ability of gas bubbles to induce radial momentum transfer [10]. As any separation process, adsorption efficiency is a complex attribute dependent on the kinetic and equilibrium properties of the adsorbate/adsorbent system. Detailed equilibrium and kinetic studies are needed to describe the mechanism of gas stirring during adsorption process.

The aim of this work is to investigate the effect of gas stirring technique on both equilibrium and kinetics of adsorption of Maxilon Red BL-3 onto natural clay as a low cost material using gas mixing technique. Gas sparging column (with no liquid flow) was used as a means of enhancing the rate of adsorption. Two parameters sorption isotherm models were employed for fitting the equilibrium data. Pseudo first-order, pseudo second-order, Elovich and fractional power equations were used for modeling the kinetics of dye adsorption. 


\section{Materials and Methods}

\subsection{Materials}

Natural clay was collected from El-Minia Governorate, Egypt. In a previous study, this type of clay was found to be consist of montmorillonite type combined with minor Kaolinite. The specific surface area of this clay is $65 \mathrm{~m}^{3} / \mathrm{g}$ [11]. Clay was crushed, ground to a fine powder and sieved, particle size used is in the range 500-700 $\mu \mathrm{m}$. Clay was used without any pretreatment. Dyestuff was Basic Red 22 (Maxilon Red BL-3, Ciba Geigy) and its chemical structure is illustrated as,<smiles>CCN(CC)c1ccc(N=Nc2n(C)cn[n+]2C)cc1</smiles>

Structure of Maxilon Red BL-3

\subsection{Experiments}

Adsorption equilibrium experiments have been undertaken to assess the efficiency of natural clay to remove Maxilon Red dye from aqueous solutions and also in finding isotherm constants. The experiments were performed by using a set of $50 \mathrm{ml}$ dye solutions of consecutively increasing concentrations which brought into contact $0.1 \mathrm{~g}$ of clay. Upon equilibrium (2 days) the samples were analyzed using a Spectra-Plus MKS spectrophotometer at a wavelength corresponding to maximum absorbance, $\lambda_{\max }=538 \mathrm{~nm}$. The amount of dye adsorbed onto natural clay at equilibrium, $\mathrm{q}_{\mathrm{e}}$, was computed by,

$$
q_{e}=V\left(C_{0}-C_{e}\right) / M
$$

where, $C_{0}$ and $C_{e}$ are the initial and equilibrium concentrations respectively $(\mathrm{mg} / \mathrm{l}), \mathrm{V}$ the volume of solution $\left(\mathrm{cm}^{3}\right)$ and $\mathrm{M}$ is the adsorbent dose $(\mathrm{g})$.

The effects of kinetic parameters such as, gas flow rate, initial dye concentration and temperature of dye solution on the adsorptive removal of dye were studied. The experiments were carried out in a cylindrical glass column of $60 \mathrm{~cm}$ height and $6 \mathrm{~cm}$ inside diameter. The column was fitted at its bottom with a G4 sintered-glass distributor of a pore diameter of 5-10 microns. Next to the gas distributor a ball valve was fixed to control nitrogen flow rate. Temperature was adjusted by passing hot water, thermostatically controlled, in a glass jacket around the column. Figure 1 represents a schematic diagram for the experimental unit. After adjusting the gas-flow rate, the column was filled with one liter of fresh dye solution at a certain concentration, followed by the addition of $2 \mathrm{~g}$ clay. The $\mathrm{N}_{2}$ flow rate was measured with a calibrated rotameter. At appropriate time intervals of $10 \mathrm{~min}$, samples were taken and analyzed to determine the residual dye concentration and then returned to the tank quickly to prevent any change in the volume of solution. The amount of dye adsorbed at any time $\mathrm{q}_{\mathrm{t}}$ was computed as,

$$
q_{t}=V\left(C_{0}-C_{t}\right) / M
$$

where, $C_{t}$ is the concentration of dye at any time during the adsorption process. 


\subsection{Validity of adsorption isotherms}

Beside the correlation coefficient $\left(\mathrm{R}^{2}\right)$, the Marquardt's percent standard deviation (MPSD) and the hybrid error function (HYBRID) were also used to measure the goodness of fit. MPSD and HYBRID can be defined as,

$$
\begin{aligned}
& M P S D=100 \sqrt{\frac{1}{N-P} \sum_{i=1}^{N}\left(\frac{q_{e i}^{\text {exp }}-q_{e i}^{c a l}}{q_{e i}^{\exp }}\right)^{2}} \\
& H Y B R I D=\frac{100}{N-P} \sum_{i=1}^{N}\left(\frac{\left(q_{e i}^{\text {exp }}-q_{e i}^{c a l}\right)^{2}}{q_{e i}^{\text {exp }}}\right)
\end{aligned}
$$

where, $q_{e i}^{\text {exp }}$ is the measured from the batch experiment, $q_{e i}^{c a l}$ is the estimated from the isotherm for corresponding $q_{e i}^{\text {exp }}, \mathrm{N}$ is the number of measurements in the experimental isotherm and $\mathrm{P}$ is the number of parameters in the regression model. Smaller values of MPSD and HYBRID indicate more accurate estimation of $\mathrm{q}_{\mathrm{e}}$ values [12].

\subsection{Validity of kinetic models}

The applicability of the kinetic model to describe the adsorption process, apart from the correlation coefficient $\left(\mathrm{R}^{2}\right)$, was further validated by the normalized standard deviation (NSD), and average relative error (ARE) which are defined as,

$$
\begin{aligned}
& N S D=100 \sqrt{\frac{1}{N-1} \sum_{i=1}^{N}\left[\frac{q_{t}^{\text {exp }}-q_{t}^{c a l}}{q_{t}^{\exp }}\right]_{i}^{2}} \\
& A R E=\frac{100}{N} \sum_{i=1}^{N}\left|\frac{q_{t}^{\exp }-q_{t}^{c a l}}{q_{t}{ }^{\exp }}\right|_{i}
\end{aligned}
$$

where, $q_{t}^{\text {exp }}$ and $q_{t}^{\text {cal }}$ are the experimental and estimated amount of dye adsorbed onto natural clay at time $t$ and $\mathrm{N}$ is the number of measurements. Smaller values of NSD and ARE indicate best fitting for the experimental data [13].

\section{Results and Discussion}

\subsection{Equilibrium isotherms}

An equilibrium isotherm expresses the relation between the amounts of adsorbate removed from solution at equilibrium by unit mass of adsorbent at constant temperature. In this study, equilibrium data were fitted by a number of "two parameters isotherm" including Freundlich, Temkin, Dubinin -Radushkevich and Langmuir. Langmuir model can be linearized into at least four different types as shown in Table 1. The relative parameters of Freundlich, Temkin, Dubinin -Radushkevich isotherms are also given in Table 1. The linear regression method of least squares is used to calculate the different parameters. 
Table 1: Isotherm models and their linearized expression.

\begin{tabular}{|c|c|c|c|c|c|}
\hline Isotherm & Equation & Linear expression & Plot & Parameters & Ref. \\
\hline Freundlich & $q_{e}=K_{F}\left(C_{e}\right)^{1 / n}$ & $\ln q_{e}=\ln K_{F}+(1 / n) \ln C_{e}$ & $\ln q_{e} v s \cdot \ln C_{e}$ & $K_{F} \& n$ & {$[14,15]$} \\
\hline Temkin & $q_{e}=q_{m} \ln \left(K_{T} C_{e}\right)$ & $q_{e}=q_{m} \ln K_{T}+q_{m} \ln C_{e}$ & $q_{e} v s \cdot \ln C_{e}$ & $K_{T} \& q_{m}$ & {$[15,16]$} \\
\hline $\begin{array}{l}\text { Dubinin- } \\
\text { Radushkevich }\end{array}$ & $\begin{array}{l}q_{e}=q_{m} \exp \left(-D \varepsilon^{2}\right) \\
\text { where, } \varepsilon=R T \ln \left(1+1 / C_{e}\right)\end{array}$ & $\ln q_{e}=\ln q_{m}-D \varepsilon^{2}$ & $\ln q_{e} v s \cdot \varepsilon^{2}$ & $q_{m} \& D$ & {$[12,15]$} \\
\hline \multirow[t]{2}{*}{ Langmuir } & $q_{e}=\left(q_{m} K_{L} C_{e}\right) /\left(1+K_{L} C_{e}\right)$ & & & & {$[15]$} \\
\hline & & $\begin{array}{l}\text { Type I: } C_{e} / q_{e}=1 /\left(q_{m} K_{L}\right)+C_{e} / q_{m} \\
\text { Type II: } 1 / q_{e}=1 /\left(q_{m} K_{L} C_{e}\right)+1 / q_{m} \\
\text { Type III: } q_{e}=q_{m}+q_{e} /\left(K_{L} C_{e}\right) \\
\text { Type IV: } q_{e} / C_{e}=K_{L} q_{m}-K_{L} q_{e}\end{array}$ & $\begin{array}{l}C_{e} / q_{e} v s . C_{e} \\
1 / q_{e} v s \cdot 1 / C_{e} \\
q_{e} v s \cdot q_{\mathrm{e}} / C_{e} \\
q_{e} / \mathrm{C}_{\mathrm{e}} v s \cdot \ln q_{e}\end{array}$ & $\begin{array}{l}K_{L} \& q_{m} \\
K_{L} \& q_{m} \\
K_{L} \& q_{m} \\
K_{L} \& q_{m}\end{array}$ & \\
\hline
\end{tabular}

The Freundlich isotherm model is often used for heterogeneous surface energy systems. The heat of adsorption decreases in magnitude with increasing of adsorption. If the decline in heat of adsorption is logarithmic, it implies that adsorption sites are distributed exponentially with respect to an adsorption energy which differs between groups of adsorption sites. Values of $\mathrm{K}_{\mathrm{F}}$ and $1 / \mathrm{n}$ are Freundlich constants related to adsorption capacity and intensity of adsorption, respectively. The lower fractional value of $1 / n[0<1 / n<1]$ indicates that weak adsorptive forces are effective on the surface of adsorbent [17]. On the other hand, the Temkin model considered the effects of indirect adsorbate/adsorbate interactions on adsorption isotherms $[14,16]$. As a result of adsorbate/adsorbate interactions, the heat of adsorption of all the molecules in the layer would decrease linearly with coverage [16]. Finally, the DubininRadushkevich model assumes that the amount adsorbed corresponding to any adsorbate concentration is Gaussian function of the Polany Potential [17]. It is well known that the Langmuir adsorption model describes monolayer adsorption of adsorbate onto a homogeneous adsorbent surface [18]. Moreover, there is negligible interaction between the adsorbed molecules and adsorption sites having uniform energies [19]. The isotherm constants and correlation coefficients which were calculated from the least square method beside, Marquardt's percent standard deviation (MPSD) and the hybrid error function (HYBRID) are listed in Table 2.

Table 2: Isotherm parameters for the adsorption of Basic Red 22 onto natural clay.

\begin{tabular}{lllll}
\hline Isotherm & $\mathrm{R}^{2}$ & MPSD & HYBRID & Parameters \\
\hline Freundlich & 0.753 & 14.338 & 466.019 & $\mathrm{~K}_{\mathrm{F}}=136.671 \mathrm{mg} / \mathrm{g} .(1 / \mathrm{mg})^{1 / \mathrm{n}}, \mathrm{n}=5.008$ \\
\hline Temkin & 0.817 & 13.185 & 341.652 & $\mathrm{q}_{\mathrm{m}}=48.963 \mathrm{mg} / \mathrm{g}, \mathrm{K}_{\mathrm{T}}=9.6821 / \mathrm{mg}$ \\
\hline Dubinin-Radushkevich & 0.940 & 5.357 & 68.751 & $\mathrm{q}_{\mathrm{m}}=317.5 \mathrm{mg} / \mathrm{g}, \mathrm{D}=0.5\left(10^{-5}\right) \mathrm{mol}^{2} / \mathrm{kJ}^{2}$ \\
\hline Langmuir & & & & \\
Type I & 0.999 & 10.503 & 176.392 & $\mathrm{q}_{\mathrm{m}}=344.83 \mathrm{mg} / \mathrm{g}, \mathrm{K}_{\mathrm{L}}=0.22141 / \mathrm{mg}$ \\
Type II & 0.968 & 5.646 & 89.966 & $\mathrm{q}_{\mathrm{m}}=370.37 \mathrm{mg} / \mathrm{g}, \mathrm{K}_{\mathrm{L}}=0.1311 \mathrm{l} / \mathrm{mg}$ \\
Type III & 0.989 & 5.318 & 65.242 & $\mathrm{q}_{\mathrm{m}}=359.23 \mathrm{mg} / \mathrm{g}, \mathrm{K}_{\mathrm{L}}=0.1511 \mathrm{l} / \mathrm{mg}$ \\
Type IV & 0.918 & 5.338 & 75.507 & $\mathrm{q}_{\mathrm{m}}=365.95 \mathrm{mg} / \mathrm{g}, \mathrm{K}_{\mathrm{L}}=0.13891 / \mathrm{mg}$ \\
\hline
\end{tabular}

The applicability of the isotherm equation to describe the adsorption process was judged by the correlation coefficient, $\mathrm{R}^{2}$, values. The adsorption isotherm models fitted the experimental data in the following order: Langmuir, Dubinin-Radushkevich, Temkin and Freundlich isotherm. Between different linear types of Langmuir model, type I best represent the equilibrium data. 
In Fig. 2 the prediction of the amount of adsorption at equilibrium by various equilibrium isotherm models was plotted against the experimental values. As shown in Fig. 2, the difference between experimental and calculated values by Langmuir-type $I$ is very low thereby is showing that, this model is the best isotherm for predicting of the amount of dye adsorbed by natural clay at equilibrium. MPSD and HYBRID values in Table 2, also suggest that Langmuir-type I isotherm provides a better model of the sorption system. The good fit of the Langmuir model suggests that Maxilon Red adsorption is limited by monolayer coverage and the surface is relatively homogeneous in terms of functional groups and there is no significant interaction among the Maxilon Red molecules.

\subsection{Kinetic study}

Kinetic study is important to an adsorption process because it depicts the uptake rate of adsorbate, and controls the residual time of the whole adsorption process. Four kinetic models, Pseudo first-order, Pseudo second-order, Elovich and Fractional power kinetic models were selected in the present study for describing the adsorption process.

A pseudo-first order rate equation can be expressed in a linear form as,

$$
\ln \left(q_{e}-q_{t}\right)=\ln \left(q_{e}\right)-k_{1} t
$$

where, $\mathrm{q}_{\mathrm{e}}$ and $\mathrm{q}_{\mathrm{t}}$ are the amounts of dye adsorbed at the equilibrium and time $\mathrm{t}$ respectively, and $\mathrm{k}_{1}$ is the rate constant of adsorption. Values of $\mathrm{k}_{1}$ were calculated from the plots of $\ln \left(\mathrm{q}_{\mathrm{e}} \mathrm{e}^{-}\right.$ $\mathrm{q}_{\mathrm{t}}$ ) versus $\mathrm{t}$ for different operating variables: gas flow rate, initial dye concentration and temperature.

The pseudo-second order model is expressed in a linear form as shown in the following equation,

$$
\frac{t}{q_{t}}=\frac{1}{k_{2} q_{e}^{2}}+\frac{t}{q_{e}}
$$

where, $\mathrm{k}_{2}$ is the rate constant of pseudo-second order adsorption. The values of $\mathrm{k}_{2}, \mathrm{q}_{\mathrm{e}}$ and $\mathrm{h}=$ $\left(\mathrm{k}^{2} \mathrm{q}_{\mathrm{e}}^{2}\right)$ can be extracted from the gradient and intercept of plotting $\left(\mathrm{t} / \mathrm{q}_{\mathrm{t}}\right)$ versus $\mathrm{t}$.

The Elovich kinetic equation [20] is generally expressed as,

$$
\frac{d q_{t}}{d t}=\alpha \exp \left(-\beta q_{t}\right)
$$

where $\alpha$ is the initial adsorption rate and $\beta$ is the desorption constant during any one experiment. To simplify the Elovich equation, $\alpha \beta \mathrm{t}>>\mathrm{t}$ is assumed and by applying the boundary conditions $\mathrm{q}_{\mathrm{t}}=0$ at $\mathrm{t}=0$ and $\mathrm{q}_{\mathrm{t}}=\mathrm{q}_{\mathrm{t}}$ at $\mathrm{t}=\mathrm{t}$, Eq. (9) becomes:

$$
q_{t}=\frac{\ln (\alpha \beta)}{\beta}+\frac{1}{\beta} \ln (t)
$$

If the adsorption data fits the Elovich model, a plot of $\mathrm{q}_{\mathrm{t}}$ versus $\ln (\mathrm{t})$ should a linear relationship with a slop of $(1 / \beta)$ and an intercept of $(1 / \beta) \ln (\alpha \beta)$.

Fractional power models is the last one of the kinetic models used in this study. It can be written in a linear form as,

$$
\ln \left(q_{t}\right)=\ln (k)-v \ln (t)
$$

The kinetic parameters $v$ and $k$ were obtained from the slop and intercept of plotting $\ln \left(\mathrm{q}_{\mathrm{t}}\right)$ versus $\ln (\mathrm{t})$. 


\subsubsection{Effect of gas flow rate}

Mixing is an important parameter in processes involving mass transfer. The effect of gas mixing was studied on the removal of dye from aqueous solutions by varying the rate of gas flow from 30 to $100 \mathrm{~cm}^{3} / \mathrm{min}$, while keeping other parameters (initial concentration, temperature, and adsorbent dosage) constant. In general, the adsorption capacity of dye increased with time until reaching a constant value indicating that no more dye ions are to be further removed from solution, Fig. 3. The amount of dye adsorbed per unit mass of clay increased from 85 to $145 \mathrm{mg} / \mathrm{g}$ when the gas flow increased from 30 to $100 \mathrm{~cm}^{3} / \mathrm{min}$. The higher solution flow increases the turbulence around the clay particles and thus decrease the boundary layer resistance by thinning. This cusses higher rate of transfer of dye ions to the surface of the clay particles.

The experimental data treated with the above kinetic models were used to evaluate the controlling mechanism of adsorption processes. The higher correlation coefficient values and lower NSD, ARE values confirmed that the adsorption data were best represented by pseudosecond order kinetics for the entire adsorption period, Tables 3 and 4 . Values of $k_{2}$ increased from $0.5066\left(10^{-4}\right)$ to $6.0967\left(10^{-4}\right) \mathrm{g} /(\mathrm{mg}$.min. $)$ with the increase in gas flow from 30 to 100 $\mathrm{cm}^{3} / \mathrm{min}$. The increases in $\mathrm{k}_{2}$ values attributed to rising bubbles which induce axial solution flow, which moves radially when it reaches the top of the solution and finally moves radially again in the bulk of the solution. This internal circulation of the solution which moves countercurrent to the uprising gas bubbles could affect the rate of dye adsorption onto surface and inside pores of clay [11].

One example of comparison between experimental data with those predicted from the different kinetic models is shown in Fig 4. It is clear that there is a good agreement between the experimental and calculated values of pseudo-second order kinetic model at different adsorption times.

Table 3: Parameters of pseudo first order and second order kinetic models at different operating variables for adsorption of Basic Red 22 by natural clay.

\begin{tabular}{|c|c|c|c|c|c|c|c|c|c|c|c|c|}
\hline \multirow[b]{2}{*}{ Parameters } & \multirow[b]{2}{*}{$\begin{array}{l}\mathrm{q}_{\mathrm{e}, \mathrm{exp}} \\
\mathrm{mg} / \mathrm{g}\end{array}$} & \multicolumn{5}{|c|}{ Pseudo first-order kinetic model } & \multicolumn{6}{|c|}{ Pseudo second-order kinetic model } \\
\hline & & $\begin{array}{l}\mathrm{q}_{\mathrm{e}, \mathrm{cal}} \\
\mathrm{mg} / \mathrm{g}\end{array}$ & $\begin{array}{l}\mathrm{k}_{1} \\
\mathrm{l} / \mathrm{min}\end{array}$ & $\mathrm{R}^{2}$ & NSD & ARE & $\begin{array}{l}\mathrm{q}_{\mathrm{e}, \mathrm{cal}} \\
\mathrm{mg} / \mathrm{g}\end{array}$ & $\begin{array}{l}\mathrm{k}_{2}\left(10^{4}\right) \\
\mathrm{g} / \mathrm{mg} \cdot \mathrm{min}\end{array}$ & $\begin{array}{l}\mathrm{h}=\mathrm{k}_{2} \mathrm{q}_{\mathrm{e}}{ }^{2} \\
\mathrm{mg} / \mathrm{g} \cdot \mathrm{min}\end{array}$ & $\mathrm{R}^{2}$ & NSD & ARE \\
\hline \multirow{2}{*}{\multicolumn{13}{|c|}{$\underline{\mathrm{Q}}\left(\mathrm{cm}^{3} / \mathrm{min}\right) *$}} \\
\hline & 85 & 139.0 & 0.0349 & 0.929 & 121.48 & 107.5 & 172.41 & 0.5066 & 1.5059 & 0.954 & 4.23 & 3.65 \\
\hline $\begin{array}{l}30 \\
50\end{array}$ & 110 & 139.9 & 0.0368 & 0.958 & 47.90 & 42.52 & 161.29 & 1.1908 & 3.0978 & 0.965 & 6.05 & 5.01 \\
\hline 70 & 126 & 146.9 & 0.0372 & 0.949 & 16.24 & 14.88 & 147.06 & 3.4898 & 7.5473 & 0.985 & 8.99 & 4.58 \\
\hline 100 & 145 & 71.5 & 0.0258 & 0.862 & 61.51 & 58.57 & 153.85 & 6.0967 & 14.431 & 0.995 & 7.65 & 3.77 \\
\hline \multicolumn{13}{|l|}{\left.${\underline{\mathrm{C}_{0}}}_{(\mathrm{mg} / \mathrm{l})}\right)^{* *}$} \\
\hline 200 & 80 & 40.8 & 0.0207 & 0.780 & 63.76 & 60.41 & 81.97 & 11.692 & 7.8559 & 0.995 & 6.16 & 3.60 \\
\hline 300 & 100 & 65.9 & 0.0281 & 0.919 & 44.19 & 41.79 & 112.36 & 5.3018 & 6.6934 & 0.994 & 6.16 & 4.04 \\
\hline 400 & 105 & 101.6 & 0.0251 & 0.944 & 9.45 & 8.19 & 147.06 & 2.0716 & 4.4802 & 0.987 & 6.93 & 5.40 \\
\hline 500 & 110 & 139.9 & 0.0368 & 0.958 & 47.90 & 42.52 & 161.29 & 1.1908 & 3.0978 & 0.965 & 6.05 & 5.01 \\
\hline \multicolumn{13}{|l|}{$\underline{\mathrm{T}\left({ }^{\circ} \mathrm{C}\right)^{* * *}}$} \\
\hline 25 & 110 & 139.9 & 0.0368 & 0.958 & 47.90 & 42.52 & 161.92 & 1.1908 & 3.0978 & 0.965 & 6.05 & 5.01 \\
\hline 40 & 135 & 132.9 & 0.0312 & 0.962 & 4.68 & 3.31 & 172.41 & 1.7102 & 5.0836 & 0.989 & 4.21 & 3.36 \\
\hline 50 & 150 & 86.9 & 0.0255 & 0.781 & 53.24 & 50.49 & 163.93 & 3.9882 & 10.7175 & 0.988 & 7.47 & 5.74 \\
\hline 60 & 165 & 64.8 & 0.0250 & 0.735 & 72.55 & 69.08 & 169.50 & 9.7781 & 28.0928 & 0.998 & 4.76 & 2.77 \\
\hline
\end{tabular}


Table 4: Parameters of Elovich and the fractional power kinetic models at different operating variables for adsorption of Basic Red 22 by natural clay.

\begin{tabular}{|c|c|c|c|c|c|c|c|c|c|c|c|}
\hline \multirow[b]{2}{*}{ Parameters } & \multirow[b]{2}{*}{$\begin{array}{l}\mathrm{q}_{\mathrm{e}, \exp } \\
\mathrm{mg} / \mathrm{g}\end{array}$} & \multicolumn{5}{|c|}{ Elovich kinetic model } & \multicolumn{5}{|c|}{ Fractional power kinetic model } \\
\hline & & $\begin{array}{l}\alpha \\
\mathrm{mg} / \mathrm{g} \cdot \mathrm{min}\end{array}$ & $\begin{array}{l}\beta \\
\mathrm{g} / \mathrm{mg}\end{array}$ & $\mathrm{R}^{2}$ & NSD & ARE & $\begin{array}{l}\mathrm{k} \\
\mathrm{mg} / \mathrm{g} \cdot \mathrm{h}^{\mathrm{v}}\end{array}$ & $\mathrm{V}$ & $\mathrm{R}^{2}$ & NSD & ARE \\
\hline \multicolumn{12}{|l|}{$\mathrm{Q}\left(\mathrm{cm}^{3} / \mathrm{min}\right)^{*}$} \\
\hline 30 & 85 & 3.462 & 0.0293 & 0.983 & 8.48 & 4.99 & 2.893 & 0.7286 & 0.975 & 7.49 & 5.91 \\
\hline 50 & 110 & 6.131 & 0.0259 & 0.958 & 7.31 & 5.91 & 8.961 & 0.5441 & 0.955 & 7.44 & 6.07 \\
\hline 70 & 126 & 14.727 & 0.0298 & 0.902 & 9.38 & 6.22 & 22.486 & 0.3812 & 0.835 & 11.33 & 8.89 \\
\hline 100 & 145 & 47.647 & 0.0359 & 0.823 & 8.79 & 5.96 & 44.256 & 0.2580 & 0.764 & 9.50 & 7.34 \\
\hline \multicolumn{12}{|l|}{$\underline{\mathrm{C}}_{0}(\mathrm{mg} / \mathrm{l})^{* *}$} \\
\hline 200 & 80 & 20.993 & 0.0641 & 0.902 & 6.91 & 5.56 & 21.287 & 0.2819 & 0.865 & 8.59 & 7.13 \\
\hline 300 & 100 & 13.912 & 0.0409 & 0.932 & 7.51 & 5.55 & 18.471 & 0.3708 & 0.883 & 10.41 & 8.20 \\
\hline 400 & 105 & 8.681 & 0.0285 & 0.953 & 6.38 & 5.37 & 10.904 & 0.5173 & 0.922 & 11.61 & 9.29 \\
\hline 500 & 110 & 6.131 & 0.0259 & 0.958 & 7.31 & 7.31 & 8.961 & 0.5441 & 0.955 & 7.91 & 6.07 \\
\hline \multicolumn{12}{|l|}{$\mathrm{T}\left({ }^{\circ} \mathrm{C}\right)^{* * *}$} \\
\hline 25 & 110 & 6.131 & 0.0259 & 0.958 & 7.31 & 5.91 & 8.961 & 0.5441 & 0.955 & 7.44 & 6.07 \\
\hline 40 & 135 & 10.170 & 0.0248 & 0.976 & 34.01 & 29.31 & 14.211 & 0.4891 & 0.959 & 7.65 & 6.18 \\
\hline 50 & 150 & 21.638 & 0.0278 & 0.903 & 8.14 & 6.57 & 28.503 & 0.3629 & 0.872 & 10.78 & 8.81 \\
\hline 60 & 165 & 181.549 & 0.0406 & 0.864 & 5.98 & 4.44 & 67.748 & 0.1927 & 0.829 & 6.76 & 5.35 \\
\hline
\end{tabular}

\subsubsection{Effect of initial concentration}

On changing the initial concentration from 200 to $500 \mathrm{mg} / \mathrm{l}$ the amount adsorbed increased from 80 to $110 \mathrm{mg} / \mathrm{g}$, Tables 3 (figure not present). This may be attributed to an increase in the driving force due to concentration gradient with the increase in the initial dye concentration in order to overcome all mass transfer resistance between the aqueous and solid phases. Therefore, a higher initial concentration of dye may increase the adsorption capacity. The kinetic parameters were calculated for the different kinetic models and listed in Tables 3 and 4 . The results show that, experimental data fit well with the pseudo-second order kinetic model where higher correlation coefficient and lower NSD, ARE were obtained.

The values of the second order rate constant, $\mathrm{k}_{2}$, were found to decrease from $11.692\left(10^{-4}\right)$ to $1.1908\left(10^{-4}\right) \mathrm{g} /(\mathrm{mg} . \mathrm{min}$.) as the initial concentration increased from 200 to $500 \mathrm{mg} / \mathrm{l}$, proving that the process is highly concentration dependent, which is consistent with previous work [21]. The values of the initial adsorption rates, determined from the straight line plots for each adsorbent system, decreased with increase in the initial dye concentration as listed in Table 3.

\subsubsection{Effect of Temperature}

Results of experiment carried out at different temperatures are shown Tables 3 and 4 (figure not present). The amount of dye adsorbed has a direct proportion with temperature; it increased from 110 to $165 \mathrm{mg} / \mathrm{g}$ as temperature increased from 25 to $60{ }^{\circ} \mathrm{C}$ means the process is chemical adsorption.

The experimental data were examined by the above mentioned kinetic models. The kinetic parameters, correlation coefficient, NSD and ARE were calculated and listed in Tables 3 and 4. As can seen from tables, the model which provided the best correlation with experimental data was the pseudo-second order kinetic model (high correlation coefficients and lower NSD, ARE values) and this will be used to analyses the experimental batch gas adsorber data. The second order rate constant, $\mathrm{k}_{2}$, was found to increase from $1.1908\left(10^{-4}\right)$ to $9.7781\left(10^{-4}\right)$ 
when temperature increases from 25 to $60^{\circ} \mathrm{C}$. Increase of temperature decreases the viscosity of dye solution. Therefore, the mass transfer coefficient tends to increase with decreasing solution viscosity, probably because of the increase of dye ion diffusivity owing to the decrease in the diffusion layer thickness at the surface of the clay particles.

The correlation coefficient, NSD and ARE for the pseudo-second order equation ranged between 0.954 and $0.998,4.21$ and 8.99 and 2.77 and 5.74 respectively. Furthermore, the calculated $\mathrm{q}_{\mathrm{e}}$ value through this model is closed to the experimental value. This strongly suggests that the adsorption of Maxilon Red dye onto natural clay is most appropriately represented by a pseudo-second order kinetic model.

\subsection{Single stage batch adsorber}

Adsorption process proceeds through varies mechanism such as external mass transfer of solute onto adsorbent followed by intraparticle diffusion. Unless extensive experimental data are available concerning the specific sorption application design procedures based on sorption equilibrium conditions are the most common methods to predict the adsorber size and performance. Previously, sorption isotherm relations have been used to predict the design of single stage batch adsorption system [22]. A schematic diagram of a single stage batch adsorption is shown in Fig. 5. The design objective is to reduce the dye solution volume $\mathrm{V}(\mathrm{l})$ from an initial concentration of $\mathrm{C}_{0}$ to $\mathrm{C}_{1}(\mathrm{mg} / \mathrm{l})$. The amount of adsorbent is $\mathrm{M}$ and the solute loading changes from $\mathrm{q}_{0}$ to $\mathrm{q}_{1}(\mathrm{mg} / \mathrm{g})$. At time $\mathrm{t}=0, \mathrm{q}_{0}=0$ and as time proceeds the mass balance equates the dye removed from the liquid to that picked up by the solid.

The mass balance equation for the sorption system in Fig. 5 can be written as,

$$
V\left(C_{0}-C_{1}\right)=M\left(q_{1}-q_{0}\right)=M q_{1}
$$

At equilibrium conditions, $\mathrm{C}_{1} \rightarrow \mathrm{C}_{\mathrm{e}}$ and $\mathrm{q}_{1} \rightarrow \mathrm{q}_{\mathrm{e}}$

Since the adsorption isotherm studies confirm that the equilibrium data fitted well in Langmuir isotherm, Langmuir isotherm equation can be used for $\mathrm{q}_{1}$ in the design equation (Eq.12) and can be rearranged as,

$$
\frac{M}{V}=\frac{C_{0}-C_{1}}{q_{1}}=\frac{C_{0}-C_{e}}{q_{e}}=\frac{C_{0}-C_{e}}{\left[\frac{q_{m} K_{L} C_{e}}{1+K_{L} C_{e}}\right]}
$$

Figure 6 shows a series of plots derived from Eq. (13) for the adsorption of Maxilon Red dye onto natural clay and depicts the amount of effluent which can be treated to remove the dye content by $75 \%$ of different initial dye concentrations using various masses of the adsorbent.

\section{Conclusions}

Effect of gas stirring on equilibrium and kinetics for adsorption of Maxilon Red from aqueous solutions onto natural clay in the range of concentration $200-500 \mathrm{mg} / \mathrm{l}$, temperature $25-60{ }^{\circ} \mathrm{C}$ and gas flow $30-100 \mathrm{~cm}^{3} / \mathrm{s}$ were studied. The equilibrium data has been analyzed using different models including Freundlich, Temkin, Dubinin-Radushkevich and four different linearized forms of Langmuir isotherm. Type I of the Langmuir isotherm was demonstrated to provide the best fit and the monolayer adsorption capacity was found $344.83 \mathrm{mg} / \mathrm{g}$ at $25^{\circ} \mathrm{C}$. Discussion on the suitability of first-order, pseudo second-order, Elovich and fractional power 
kinetic models for the adsorption process proved that, the adsorption kinetics of Maxilon Red onto natural clay obeyed second-order adsorption kinetics. A single stage batch adsorber was designed for different initial dye concentration to calculate volume of effluent treated as a function of adsorbent dosage when $75 \%$ dye removal is required.

\section{References}

[1] A.B. des Santos, F.J. Cerantes and J.B. Van Lier, Review paper on current technologies for decolourisation of textile wastewater: perspectives for anaerobic biotechnology, Bioresour. Technol, 98 (2007) 2369-2378.

[2] N. Dizge, C. Ayiner, E. Demirbas, M. Kobya and S. Kara, Adsorption of reactive dyes from aqueous solutions by fly ash: kinetic and equilibrium studies, J. Hazard. Mater., 150 (2008) 737-746.

[3] C. Bilgic, Investigation of the factors affecting organic cation adsorption on some silicate minerals, Journal of Colloid and Interface Science, 281 (2005) 33-38.

[4] S.K. Kawatra and S.J. Ripke, Developing and understanding the bentonite fiber bonding mechanism, Mining Engineering, 14 (2001) 647-659.

[5] C.C. Wang, L.C. Juang, T.C. Hsu, C.K. Lee and F.C. Huang, Adsorption of basic dyes onto montaminants, Journal of Colloid and Interface Science, 273 (2004) 80-86.

[6] S.H. Lin, R.S. Juang and Y.H. Wang, Adsorption of acid dye from water onto pristine and acid activated clays in fixed beds, Journal of Hazardous Materials B 113 (2004) 195-200.

[7] M.M. Nassar and H.M. Yehia, Mass transfer during adsorption of basic dye on clay in fixed bed, Indian Chem. Eng., 41, 1 (1999) T27-T30.

[8] M.M. Nassar, O.A. Fadali and A.A. Reda, Gas stirring technique for adsorption of dyes onto montmorillonite clay, Sustainable Energy and Environmental Technology-Asian Pacific Conf., Ed. Hu and Yue, World Publisher, Hong Kong, (2001) 479-487.

[9] O.A. Fadali, Gas stirring to enhance mass transfer during extraction of copper by Naphthenic acid, Journal of Basic Science and Engineering, 12, 3 (2004) 233-239.

[10] L.S. Fan, T.S. Ramash, W.T. Tang and T.R. Long, Gas liquid mass transfer in a two stage draft tube gas-liquid fluidized bed, Chemical Engineering Science, 42 (1984) 543553.

[11] M.M. Nassar, T.E. Farrag and J.Y. Farah, Gas sparged adsorber for decolourization dye effluent, Eurasian Chem Tech Journal, 9 (2007)147-152.

[12] K. Vasanth Kumar, K. Prokodi and F. Rocha, Isotherms and thermodynamics by linear and non-linear regression analysis for the sorption of methylene blue onto activated carbon: comparison of various error functions, J. Hazard. Mater. 160 (2008) 794-804.

[13] B.H. Hammed and A.A. Rahma, Removal of phenol from aqueous solutions by adsorption onto activated carbon prepared from biomass material, J. Hazard. Mater. 160 (2008) 576-581.

[14] K. Li, Z. Zheng, X. Huang, G. Zhao, J. Feng and J. Zhang, Equilibrium, kinetics, thermodynamic studies on the adsorption of 2-nitroaniline onto activated carbon prepared from cotton stalk fiber, J. Hazard Mater, 166 (2009) 213-220. 
[15] Y. Khambhaty, K. Mody, S. Basha and B. Jha, Kinetics equilibrium and thermodynamics studies on biosorption of hexavalent chromium by dead fungal biomass of marine Aspergillus niger, Chem. Eng. J., 145 (2009) 489-495.

[16] R. Han, J Zhang, P. Han, Y. Wang, Z. Zhao and M. Tang, Study of equilibrium, kinetic and thermodynamic parameters about methylene blue adsorption onto natural Zeolite, Chem. Eng. J., 145 (2009) 496-504.

[17] C. Hsieh and H. Teng, Influence of mesopore volume and adsorbate size on adsorption capacities of activated carbons in aqueous solutions, Carbon 38 (2000) 863-869.

[18] A. El Nemr, Potential of pomegranate husk carbon for $\mathrm{Cr}(\mathrm{VI})$ removal from wastewater: kinetic and isotherm studies, J. Hazard. Mater. 161 (2009) 132-141.

[19] K.G. Sreejalekshmi, K. Anoop Krishnan and T.S. Anirudhan, Adsorption of Pb(II) and $\mathrm{Pb}$ (II)-citric acid an sawdust activated carbon: kinetic and equilibrium isotherm studies, J. Hazard. Mater, 161 (2009) 1506-1513.

[20] S.H. Chien and W.R. Clayton, Application of Elovich equation to the kinetics of phosphate release and sorption in soils, Soll. Sci. Soc. Am. J., 44 (1980) 265-268.

[21] S. Chegrouche, A. Mellah and M. Barkat, Removal of strontium from aqueous solutions by adsorption onto activated carbon: kinetic and thermodynamic studies, Desalination 235 (2009) 306-318.

[22] V. Vadivelan and K.V. Kumar, Equilibrium, kinetics, mechanism, and process design for the sorption of methylene blue onto rice husk, Journal of Colloid and Interface Science, 286 (2005) 90-100. 


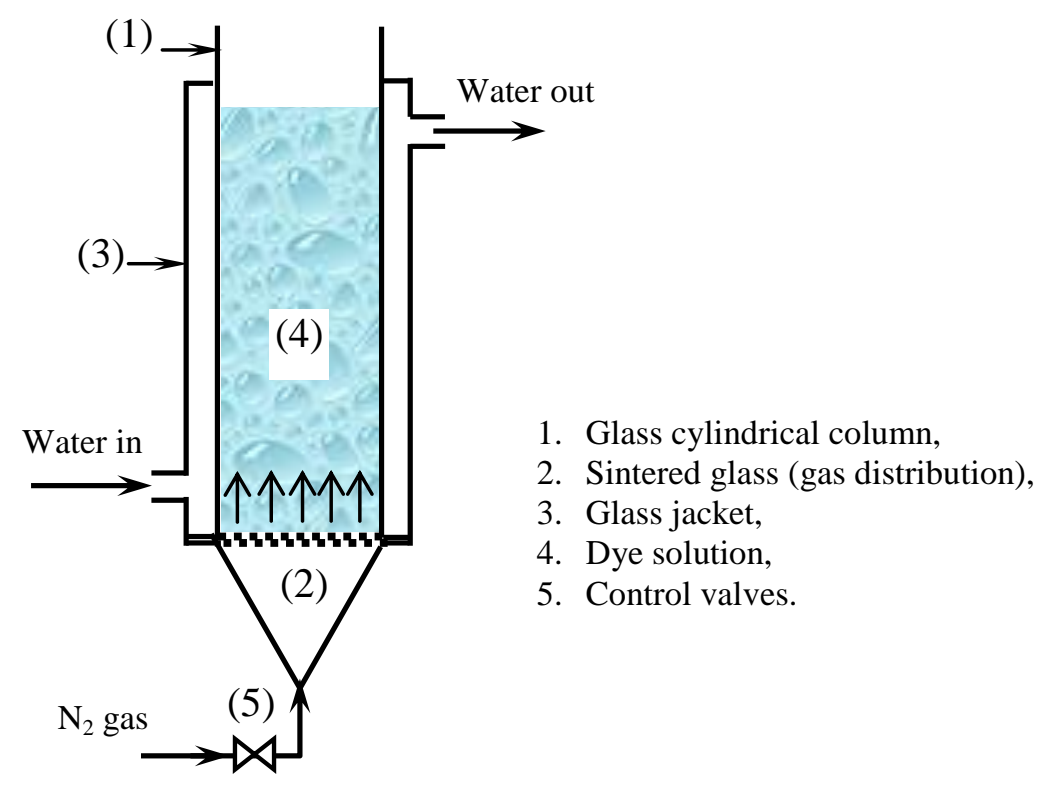

Fig. 1: Schematic diagram for the experimental unit

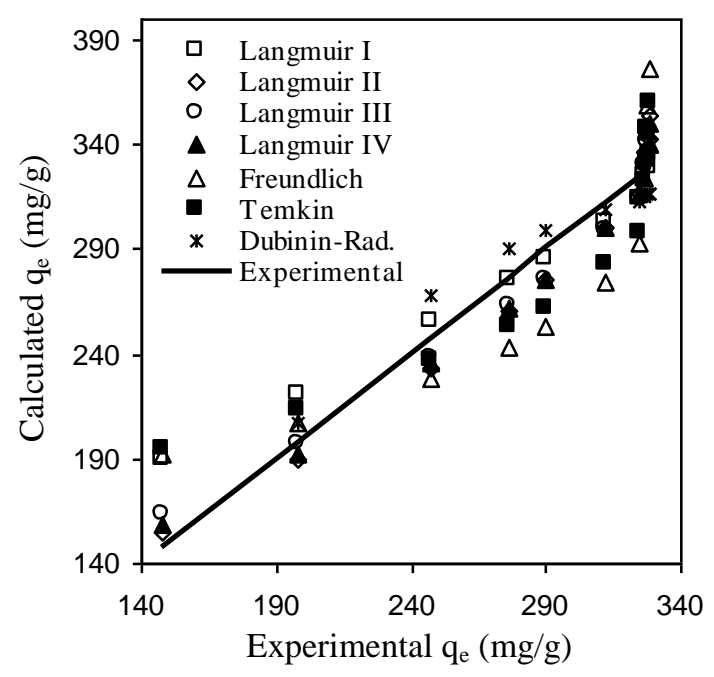

Fig. 2: Amount of adsorbed dye at equilibrium $\left(\mathrm{q}_{\mathrm{e}}\right)$ calculated by different isotherm models compared with the experimental values.

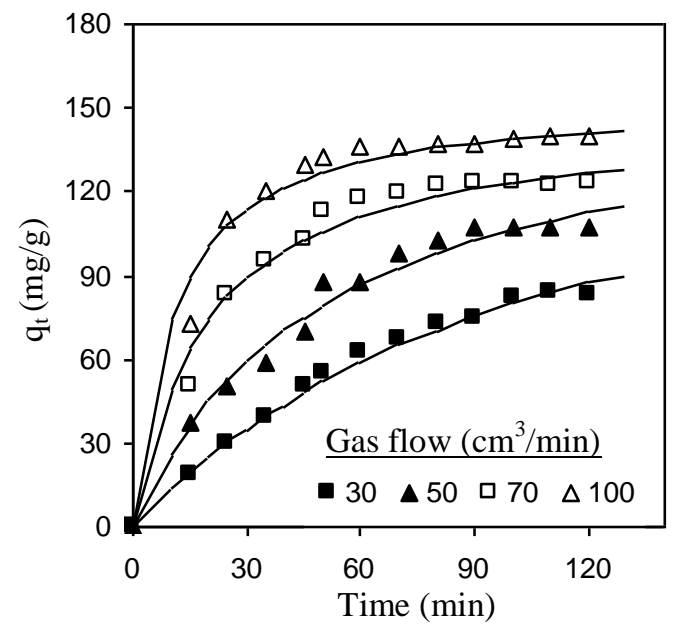

Fig. 3. Amount of dye adsorbed as a function of time at different gas flow rates. Symbols are experimental values and lines are the calculated values by pseudo-second order kinetic model, $\mathrm{C}_{0}=500 \mathrm{mg} / \mathrm{l}, \mathrm{m}=2 \mathrm{~g}$ and $\mathrm{T}=25 \pm 1{ }^{\circ} \mathrm{C}$. 


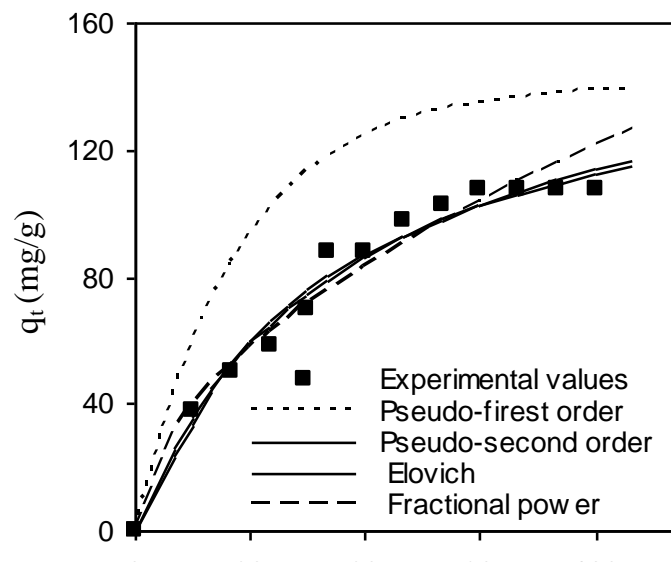

Fig. 4: Amount of dye adsorbêd as a function of time for $50 \mathrm{~cm}^{3} / \mathrm{min}$ gas flow. Symbols are experimental values, and lines are the calculated values by different kinetic models, $\mathrm{C}_{0}=500 \mathrm{mg} / \mathrm{l}, \mathrm{m}=2 \mathrm{~g}$ and $\mathrm{T}=25 \pm 1{ }^{\circ} \mathrm{C}$.

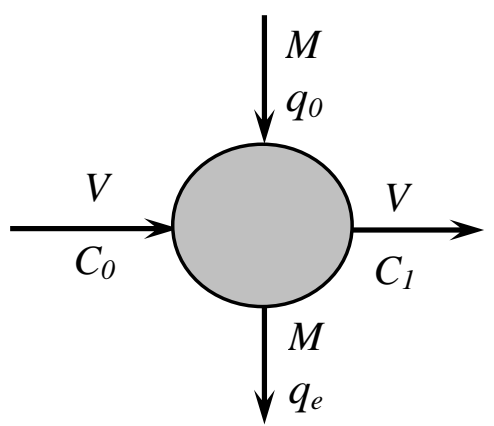

Fig. 5. A single-stage batch adsorber.

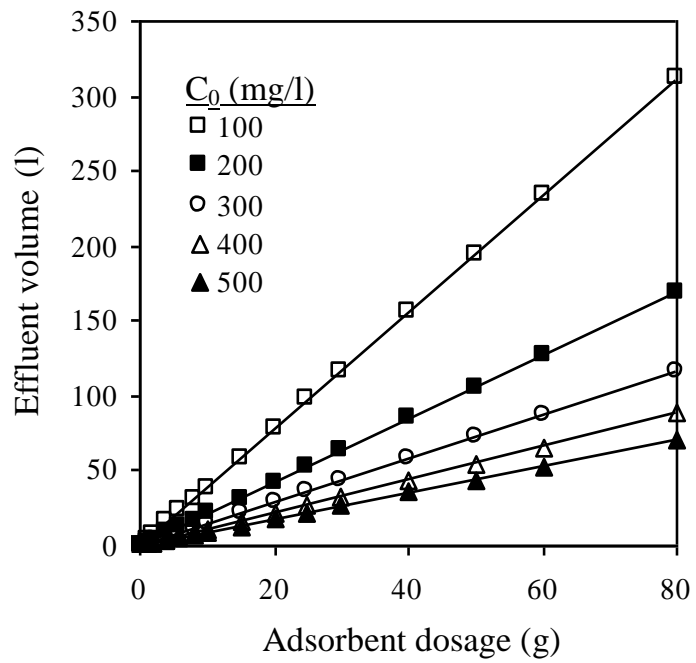

Fig. 6. Volume of effluent treated versus mass of natural clay for $75 \%$ dye removal at different initial dye concentrations. 